\title{
TRIESTE: DA LÙNEDI A KÒSOVEL
}

La ritrazione dell'accento tronco di due o tre sillabe è considerato dai più fenomeno tipico del dialetto triestino. Il fenomeno si ripercuote nell'onomastica cognominale veneta, ma pure in quella dell'immediato entroterra sloveno della città.

Sembra che la ritrazione dell'accento dalla sillaba finale per due o addirittura tre sillabe (lùnedi, màrtedi, mèrcoledi, giòvedi, vènerdi), tipica del dialetto triestino, non sia stata finora trattata da alcun linguista. Ho speso un po' di tempo per cercare qualcosa, ma l'amico Mario Doria mi conforta assicurandomi di non conoscere alcuno studio in proposito. Parto dunque da un presupposto accettato e dato per scontato da molti (da tutti?). Se l'argomento in sé riguarda direttamente gli esperti di dialettologia italiana, da slavista datato e onomasta consumato mi esimo dall'esperire alcunché di nuovo in merito (videant consules!) per rivolgere la mia attenzione ai cognomi, italiani e sloveni, della città e del suo immediato entroterra sloveno.

E inizio con la constatazione che molti cognomi etnici di origine veneta cambiano, a Trieste, obbligatoriamente l'accento. Così l'etnico e cognome veneto Padovàn trasmuta a Trieste in Pàdovan, così Trevisàn in Trèvisan: la $e$ aperta triestina, che potrei definire 'a sbregabalòn', rende la differenza di accento e di pronuncia ancor più dolente. E se vogliamo continuare su questa strada arriviamo alla pronuncia del nome dell'albergo Còntinental che Mario Doria in un colloquio telefonico odierno (siamo al giorno dei SS. Pietro e Paolo del 2000) mi citò come caso limite.

Se per questi cognomi Mario Doria (mi riferisco sempre all'odierno colloquio telefonico) pensa che possano aver mutato l'acento per distinzione, come in varie lande ed epoche era già successo, la cosa mi sembra plausibile. Mentre per la serie lùnedivènerdi ci si può forse (la supposizione è mia e può ritorcersi a mia infamia) riferire anche a un arcaismo periferico per la comune ascendenza di lùnedi e lunedi dal latino lūnae diēs e così via applicando.

Entro ora nel vivo delle mie competenze per sottolineare che il fenomeno attacca, come un virus, pure i cognomi sloveni dell'immediato e del meno immediato entroterra triestino (quali sono le misure, in chilometri, dell'immediatezza territoriale?).

Il primo vistoso esempio riguarda il cognome endemico, come sembra, di Prosecco e Contovello (in comune di Trieste a $6 \mathrm{~km}$ dal centro cittadino) che il notaro Giusto Ravizza scriveva nel 1525 ancòra Perovel ${ }^{1}$. Tra i proprietari di vigneti dei due insedia-

1 Perovel, in: Paolo Merkù, Il "Libro di perticazioni" del Notaro Giusto Ravizza (1525): il testo e l'analisi dei nomi personali, di istituzioni e di luoghi, Ed. Devin, Trieste, 1994, pp. 163. 
menti citati il notaro annovera Antonius Perovel de Contovello, Iacob Perovel de Prosecho, Petrus Perovel de Prosecho e T(h)omez/T(h)oma(s) Perovel(li) de Contovello. Da 18 scritture risulta univocamente la forma cognominale Perovel. Oggi il cognome suona Pàrovel: il 30 giugno 1996 a Trieste risiedevano 189 Parovel mentre la primaria forma cognominale non era più attestata ${ }^{2}$.

Per spiegare la primaria forma cognominale nel libro citato in nota 1 scrivevo: "Cognome composto con il sostantivo pero 'penna' (e una quantità di significati traslati, tra i quali possono concorrere alla genesi del cognome almeno 2. 'molla'; 3 . 'lama della sega'; 4. 'barba della chiave, punta del trapano'; 5. 'razza, raggio (della ruota)') e con la base verbale vel- (vleči 'tirare, menare'). I cognomi sloveni composti con una base verbale sono rari e sono, originariamente, soprannomi che designano un'attività (p. es. Kosovél 'colui che tira/mena la falce, il falciatore). *Perovél potrebbe quindi originariamente designare una persona che usa uno degli strumenti indicati. Il cognome sembra essere concentrato a Prosecco/Contovello ed è oggi attestato, nella forma Pàrovel con sviluppo tipicamente triestino (enfatizzazione dell' $e$ aperta atona fino a coincidere con $a$ e ritrazione dell'accento di due sillabe)..., in un'area più vasta (Trieste e provincia, Sesana e Lubiana)."

E siamo giunti, infine, al più celebre cognome Kosovél, che oggi quasi tutti accentano Kòsovel: tale forma, erronea e brutta, si è propagata da Trieste a Lubiana e a tutta la Slovenia (forza del virus!). Poiché fin da bambino udivo tutte e due le forme, chiesi (quando? sicuramente negli anni sessanta) a Tončka Kosovel, sorella minore del poeta, con la quale la famiglia di mia madre intratteneva rapporti di amicizia e che perciò da bambino chiamavo 'zia Tončka', quale fosse l'accento corretto. Al che mi rispose: 'La forma corretta è Kosovél: guai se mio padre la udiva storpiata in Kòsovel: correggeva subito l'interlocutore. Ma ormai udiamo da tanto accentare il nostro cognome in forma errata che ci siamo abituati anche noi ad usare tale forma.' Il maestro Anton Kosovel era uomo colto e sensibile. Ma il virus triestino sembra aver sconfitto la ragione e la sensibilità. E persino l'orecchio degli slovenisti (ma ne hanno, gli slovenisti?).

L'etimologia del cognome è trasparente: alla base c'è l'appellativo kósa 'falce' + la base vel-del verbo vléči 'tirare, menare'; il cognome metonimico significa quindi 'falciatore' e ripete un primo nome o soprannome di mestiere. Il cognome ha generato inoltre il toponimo Kosovélje, insediamento a $15 \mathrm{~km}$ a occidente di Sežana sul Carso triestino.

C'è ancora qualche speranza di udire il cognome correttamente pronunicato -almeno alla radio, alla televisione, nelle aule scolastiche, a teatro-o il male è irreversibile?

\section{PRESKOK NAGLASA V TRŽAŠKEM NAREČJ}

Naglasni premik od zadnjega zloga nazaj za dva ali kar tri zloge (lùnedi $<$ lunedi, mèrcoledi $<$ mercoledi) velja za posebnost tržaškega narečja, vendar ni temu pojavu doslej nihče $\mathbf{v}$ znanstvenem svetu posvetil pozornosti. Pojav se v Trstu razširi najprej na priimke iz Veneta (Padovàn $>$ Pàdovan), zatem pa - po 16. stoletju - tudi na slovenske priimke iz neposredne tržaške okolice (Perovèl > Pàrovel in Kosovél > Kòsovel).

2 Comune di Trieste, Elenco dei cognomi e delle loro frequenze al 30 giugno 1996. 